\title{
Poder vestimentario y ley de prohibición del incesto: Una lectura foucaultiana del ensayo fotográfico Los intocables del artista Eric Ravelo
}

Kira Schroeder Leiva

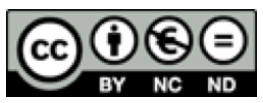

Esta obra está bajo una licencia Creative Commons Reconocimiento- No comercial-Sin Obra Derivada 

Artículos

\title{
Poder vestimentario y ley de prohibición del incesto: una lectura foucaultiana del ensayo fotográfico Los intocables del artista Eric Ravelo
}

\author{
Kira Schroeder Leiva ${ }^{1}$ \\ Universidad de Costa Rica \\ kiraschroederleiva@gmail.com
}

Recibido: 10 de febrero del 2016 Aprobado:18 de febrero de 2016

\section{Resumen}

Este ensayo es una lectura del proyecto fotográfico Los intocables del artista cubano Eric Ravelo que muestra cuerpos, cuerpos adultos y cuerpos niños, con una particular forma de relacionarse que se nos hace evidente a través de la posición en que se presentan los cuerpos y la forma en que estos cuerpos están ataviados. Estas características exponen ciertas relaciones de poder -poder vestimentario- que ordena los cuerpos y las relaciones entre ellos. En este ensayo se propone que los núcleos de poder-saber evidenciados por Ravelo en su proyecto fotográfico, articulados por el artista como relaciones sacrificiales ordenadas por una cierta forma de vestir los cuerpos, vislumbra una grilla de inteligibilidad donde los núcleos de poder producen espacios de excepción a la ley de prohibición del incesto. Además, argumenta que esta forma de develamiento crítico a través del arte que realiza Ravelo puede pensarse como un acto de un parrhesiasta tal y como lo trabaja Foucault en su libro El coraje de la verdad, entendido como un forma de enunciación de verdad en un acto creador.

Palabras clave: arte crítico, Foucault, Ravelo, poder vestimentario.

\begin{abstract}
This essay is a reading of the photographic project The untouchables created by the Cuban artist Eric Ravelo which shows bodies, adult bodies and child bodies, with a particular way of relating to each other, that is shown to the observer through the position in which the bodies are presented and the

${ }^{1}$ Este trabajo es el resultado del curso "Moda, corporalidad y poder", dictado por el Dr. Camilo Retana, a quien se le agradece su transmisión.
\end{abstract}




\section{Artículos}

way the bodies are dressed. These characteristics show a certain set of power relations, dress power that arranges the bodies and the relations among them. The author proposes that the power-knowledge nuclei evidenced through Ravelo's photographic project, articulated by the artist as sacrificial relationships given by a certain way in which the bodies are dressed, brings to light an intelligibility grid where the power nuclei produces spaces of exception of the incest prohibition law. Furthermore, the author argues that this form of critical unveiling through art that Ravelo carries out can be thought of as an act of a parrhesiasta, concept developed by Foucault in his book The courage of truth.

Keywords: critical art, Foucault, Ravelo, dress power. 
El trabajo que despliego a continuación es una lectura del ensayo fotográfico Los intocables del artista cubano Eric Ravelo, proyecto que él define como una instalación humana, y a la cual añade el subtexto "El derecho a la niñez debería ser protegido" (Ravelo, 2013, párr. 1). Seguidamente, resalto algunas particularidades de dicha propuesta. Su difusión fue hecha a través de redes sociales, tornándose "viral", y recibió una reacción muy fuerte por parte del público; alguna gente la tildó de "pornográfica", la red social Facebook la censuró y el artista recibió amenazas de muerte. La propuesta fotográfica muestra cuerpos, cuerpos adultos y cuerpos niños, con una particular forma de relacionarse que se nos hace evidente a través de la posición en que se presentan los cuerpos y la forma en que estos cuerpos están ataviados, trayendo a la luz unas ciertas relaciones de poder.

Utilizando una conceptualización foucaultiana del poder, este no sería abordado como una fuerza represiva, sino como un conjunto de relaciones que tienen efectos sobre los cuerpos. Desde esta perspectiva se hace necesario pensar estas relaciones desde la mancuerna saber-poder, en tanto no hay poder que no se ejerza a través de un saber. Cada fotografía muestra una forma en que esta mancuerna saber-poder se articula: a) el saber médico de la mano del saber del mercado para transar órganos extraídos de niños en condiciones de vulnerabilidad exacerbadas para clientes con poder adquisitivo; b) la priorización del mercado de armas y la libertad de portarlas por encima de los efectos que esto tiene sobe la vida de las niñas y niños; c) las divisas del turismo sobre las cuales se sostienen muchas economías en desarrollo que han sustituido la producción agrícola por el turismo, que trae una corriente oscura de turismo sexual -de forma específica, con menores de edad- y que los gobiernos y cámaras de empresarios turísticos y las sociedades están dispuestos a perdonar con tal de que sigan entrando los dólares; d) el saber de la iglesia sobre una moral atada a un dios, que le otorga dicho saber solamente a algunos que se proponen ellos mismos como excepción a la moral que promulgan, para así acceder a cuerpos niños y violentarlos; e) el conflicto armado como discurso que autoriza a ambos bandos a desmantelar toda institucionalidad articuladora de los derechos básicos de las niñas y niños; f) el saber sobre la tecnología de producción de energía nuclear y sus consecuencias ha sido desarrollado a pesar del pago de los cuerpos de niñas y niños puestos en riesgo; finalmente, g) la comida rápida, combinación de marketing, inmediatez, y alimentos poco nutritivos, que ha crecido como un imperio económico mundial, sobre las espaldas de los cuerpos obesos de las niñas y niños.

A continuación se desarrollarán tres ejes de lectura, a saber: poder vestimentario, estado de excepción, y el artista como Parrhesiasta. Le recomiendo al lector visitar www.erikravelo.info y observar el ensayo fotográfico antes de continuar con la lectura de este artículo. Al final del análisis presento una breve descripción del contexto al que hace alusión cada fotografía, que provee mayor información sobre cómo el fenómeno social aludido impacta la niñez. 


\section{Poder vestimentario}

Las fotografías tienen un impacto fuerte en el espectador al mostrar un adulto de espaldas, y una niña o niño cuya cara está borrada, impidiendo cualquier identificación posible de los rostros, y así exaltando la identificación de los cuerpos a través del elemento vestimentario. Se evidencia, a través de este recurso, la relevancia de los atuendos en la distribución del poder. Al respecto dice Retana en su libro Las artimañas de la moda: una genealogía del poder vestimentario:

[...] cabe en efecto la sospecha de que tras la aparente frivolidad de la moda se urden complejos mecanismos que definen normas somáticas y crean mecanismos reglamentadores, sistemas identificatorios, dispositivos de disciplinamiento, regímenes de deseo y modos de relacionamiento con el propio cuerpo y con el cuerpo de los otros. (2015, p.134)

¿Por qué podemos pensar la vestimenta como un dispositivo que regula las relaciones de poder? Siguiendo a Retana, es posible afirmar que la teorización filosófica sobre la moda ha puesto un énfasis en el problema de la difusión y ha explicado dicho problema a partir de una lucha de clases por prestigio y reconocimiento. Para el autor, esta lógica explicativa se basa en dos premisas no evidentes en una primera mirada; un cuerpo anatómico biológico desnudo en una lucha darwiniana por la supervivencia, sobre el cual la cultura despliega el vestido.
Así lo define el autor:

El cuerpo desnudo, pensado como lo opuesto al cuerpo vestido, establece así un continuum entre sociedad y naturaleza, pero al mismo tiempo fija un límite entre ambas, funcionando como una especie de concepto bisagra. En esta medida [...] la desnudez, al quedar inscrita retóricamente hablando en un marco biológico/bélico, legitima una comprensión del cuerpo como superficie de intervención del poder (2015, p.88).

Al proponer esta oposición entre cuerpo desnudo y cuerpo vestido, se produce el efecto de una cronología inversa, es decir, el cuerpo desnudo primero sobre el que actúa el vestido para producir un cuerpo vestido; precisamente, el cuerpo desnudo es una producción cultural que surge retroactivamente por la acción del poder vestimentario. No habría entonces sociedad más allá del poder, ni desnudez fuera de la cultura.

En este punto es importante detenerse y considerar el malestar del público que considera Los intocables de carácter "pornográfico" (News.com.au, 2013); es decir, aquí se plantea que la obra tendría un carácter obsceno, impúdico, que ofende al honor, la modestia, y el recato, según la Real Academia Española (2001, p. 1804). No obstante, otras definiciones de pornografía subrayan, además, un contenido sexual explícito que tiene como objetivo el de provocar a su receptor. Tendría que enfatizar que ese contenido sexual explícito justamente se enfoca en la desnudez de los cuerpos. Ahora, en las 
Artículos

fotografías de Ravelo, los cuerpos adultos están muy cubiertos, completamente vestidos, mientras que los cuerpos de los niños y niñas estarían en el camino hacia la desnudez, siendo desvestidos. Para pensar este detalle cito a Retana:

La desnudez, en síntesis, solo existe para Agamben como presupuesto, como desnudamiento; no existe una desnudez presocial: lo que existe es la institución social del desnudo. Solo hay desnudez, por tanto, en el marco de un entramado discursivo que la postule. (2015, p.113)

El carácter pornográfico de la obra de Ravelo estaría dado, entonces, por la explicitación de las discursividades que desvisten la niñez, y que son ofensivas a quienes, de maneras directa o indirecta, participamos de ellas. Las fotografías hacen visible las formas en que no vemos como desnudamos la niñez, ya que son cuerpos niños des-vistos. Si el objetivo de las instituciones o prácticas del poder es producir subjetividades, este ensayo fotográfico muestra cómo el poder vestimentario produce fenómenos de des-subjetivación, tal y como lo concibe Agamben en la siguiente cita:

Aquello que llamo nuda vida es una producción específica del poder y no un dato natural. En cuanto nos movamos en el espacio retrocedamos en el tiempo, no encontraremos jamás - ni siquiera en la condiciones más primitivas - un hombre sin lenguaje y sin cultura. Ni siquiera el niño es nuda vida: al contrario, vive en una especie de corte bizantina en la cual cada acto está siempre ya revestido de sus formas ceremoniales. Podemos, en cambio producir artificialmente condiciones en las cuales algo así como una nuda vida se separa de su contexto: el «musulmán» en Auschwitz, el comatoso, etcétera. Es en este sentido que decía antes que es más interesante indagar cómo se produce la desarticulación real del humano que especular sobre cómo ha sido producida una articulación que, por lo que sabemos, es un mitologema. (2003, p.18)

Cabe preguntarse entonces cómo estos discursos representados por la forma en que se atavían los cuerpos adultos en las fotografías, desarticulan lo humano justo en el momento de su articulación; es decir, la niñez, para producir cuerpos dóciles, con grandes limitaciones en su capacidad deseante y crítica. Intento abordar dicha cuestión más adelante en este ensayo, en el apartado sobre el estado de excepción.

Retorno al cuerpo ataviado de los adultos en las fotografías que nos presenta Ravelo. Estas, muestran el uniforme de un militar sirio; el disfraz de Ronald McDonald; el ropaje que usa el cirujano; las típicas bermudas, tenis, camisa floreada y gorra de un turista estadounidense; el equipo de protección de un funcionario de una planta nuclear que usaría durante una emergencia; el hábito de un sacerdote, y los pantalones y zapatos estilo militar, abrigo con capucha y armas en ambas manos, de un joven estadounidense expuesto a una oferta amplia de armas de fácil acceso. La vestimenta ordena y produce los cuerpos, 


\section{Artículos}

y las relaciones que estos pueden establecer con sus semejantes. Así lo explica Retana:

[...] considero que el estilo, tal y como lo señala la Escuela de Birmingham, designa asimismo un modo de relación política con la indumentaria. En este sentido, mi opinión es que es válido hablar de estilos propiamente vestimentarios (aunque nunca exclusivamente vestimentarios) toda vez que los ejercicios estilísticos involucran procedimiento en los que el cuerpo, como lo diría Merleau-Ponty, se «anexa» prendas para así ganar capacidades y posibilidades de acción. (2015, p. 33)

Así, podemos pensar las prendas que portan los hombres en las fotografías como elementos que, al mismo tiempo, disciplinan un cuerpo y le otorga unas ciertas coordenadas de acción sobre los cuerpos de los niños. La vestimenta funcionaría tanto como dispositivo ortopédico de disciplinamiento, que contribuye al ordenamiento de los cuerpos en hombres o mujeres, y al mismo tiempo habilita e impone desde esa identificación al género una cierta relación con los otros. En tanto se acata performativamente las reglas que las vestimentas exigen, se da una ganancia de aptitudes, y un cierto acceso a otros cuerpos. Mientras que las disciplinas producen un cuerpo deseante adscrito a un género y a unos ciertos códigos relacionales, la biopolítica permite distribuir los cuerpos, jerarquizándolos para producir dichos encuentros a partir de regímenes de identificación como el vestido; así, ataviados, entonces, los cuerpos adultos del ensayo de Ravelo, son reconocidos como portadores de unas ciertas capacidades, de unas ciertas licencias relacionales, que representan puntos de encuentro de discursos, institucionalidades y dispositivos que habilitan una cierta relación con los cuerpos de las niñas y niños, que son por los adultos desvestidos, $\mathrm{y}$ por la sociedad des-vistos.

El hecho de que en las fotografías los cuerpos adultos dan la espalda, muestra la impunidad que dichas vestimentas les otorga para ejercer los actos de desnudamiento. En ese mismo sentido, el borramiento de las caras de los niños, la imposibilidad de que encontremos su mirada, da cuenta de los efectos de este poder vestimentario sobre sus cuerpos y las limitaciones a su capacidad de resistencia ante el mismo. La relación entre cuerpos niños y cuerpos adultos está marcada por el signo de la crucifixión, que alude a una muerte que se alarga de manera dolorosa y que se da así en sacrificio a un gran Otro $^{2}$. La pregunta que surge entonces es ¿en nombre de quién sacrificamos a nuestras niñas y niños?

\footnotetext{
${ }^{2}$ El concepto de gran Otro es traído aquí de la teoría de Jacques Lacan. Se utiliza para referir a aquel o aquello que de razón de la existencia del sujeto, que de cuenta del sentido de su ser humano. Al lugar del gran Otro puede advenir la cultura, el lenguaje como conteniendo todas la palabras, una deidad, o un semejante, entre otros.
} 


\section{Estado de excepción}

Las vestimentas que muestran las fotos de los hombres simbolizando la cruz, son prendas que le permiten un accionar en relación con la niñez, eximiéndolos de respetar esos cuerpos infantiles, o dicho más fuertemente, les permite hacer con esos cuerpos aquello que la ley de prohibición del incesto ${ }^{3}$ impide. Así, la hipótesis a desarrollar en este apartado es que los núcleos de poder-saber evidenciados por Ravelo en su proyecto fotográfico, articulados por el artista como relaciones sacrificiales ordenadas por una cierta forma de vestir los cuerpos, vislumbran una grilla de inteligibilidad con núcleos donde las relaciones de poder producen espacios de excepción a la ley de prohibición del incesto. Los efectos de levantamiento de esta legislación la de cuerpos niños producidos como cuerpos dóciles, con grandes limitaciones en su capacidad deseante y crítica.

El concepto de estado de excepción remite a un levantamiento temporal del derecho, de la constitución, de ciertos derechos de los ciudadanos que es puesto en marcha por aquel quien detenta el poder del estado con el fin justamente de garantizar la continuidad y existencia de esas leyes que se suspenden. Al respecto dice Agamben: "El estado de excepción se presenta más bien desde esta perspectiva como un umbral de indeterminación entre democracia y absolutismo" (2003, p. 26), y en su libro titulado Estado de Excepción argumenta que dicho estado es la clave bajo la cual se puede leer la biopolítica del siglo XX. Así vemos una forma de hacer política en la cual se vive una guerra civil legal, cuyos ejemplos paradigmáticos son la detención de los judíos en campos de concentración por el régimen nazi, y la orden de guerra emitida por George W. Bush después de los ataques terroristas a Nueva York el 11 de setiembre de 2001, según el cual se autoriza la detención indefinida de sospechosos sin necesidad de una acusación penal formal.

Este concepto resulta útil para pensar estos núcleos de poder que producen campos de acción donde se levanta la ley de prohibición del incesto, estados de excepción a una ley que es la encargada de introducir a las niñas y niños en cultura. La ley de prohibición del incesto es pensada como ley universal que en toda cultura organiza los cuerpos para el disfrute de la sexualidad. Estudiada por la antropología en la figura de Levi-Strauss, y por el psicoanálisis con Freud, la exogamia es favorecida por sobre la endogamia, con fines organizadores de las relaciones sociales, económicas, y culturales, y para la producción de subjetividades o cuerpos deseantes. En su acepción moderna más común, esta prohíbe el contacto sexual entre padres y madres, e hijas e hijos, justamente inhibiendo los cuerpos adultos de aquellos encargados de erotizar, sin fines sexuales, con cuidados y palabras, los cuerpos infantiles para producirlos como seres humanos, de acceder a estos últimos con fines propios de un goce sexual adulto.

${ }^{3}$ Más adelante se desarrolla este concepto. 


\section{Artículos}

Sin embargo, de manera más amplia, dicha ley regula las generaciones, y las relaciones entre las mismas y ordena entonces los vínculos posibles entre niños y adultos. Una forma en que hemos articulado en una época de derechos humanos esta ley de prohibición del incesto es la Declaración de los Derechos del Niño, firmada por todos los estados miembros de Naciones Unidas el 20 de Noviembre de 1959, y luego la Convención Sobre los Derechos del Niño en 1989, que declaran a niñas y niños como seres humanos sujetos de derecho. Así, cuando me refiero a la ley de prohibición del incesto, intento sostener una legalidad que declararía "no puedes hacer cualquier cosa con el cuerpo de niñas y niños".

Así, este levantamiento de la ley de prohibición del incesto, constituye un uso del concepto de estado de excepción que se diferencia de su uso original desde la teoría política, en tanto que esta parte de un gobierno desde el cual un gobernante emite el estado de excepción y este está adscrito a un país geográficamente localizable. Lo que vemos en las fotografías de Ravelo es que los campos de excepción de la ley de prohibición del incesto están articulados al discurso de la globalización y la liberalización del mercado, produciéndose como fenómenos muchas veces transnacionales y su pronunciamiento no es decretado necesariamente por un gobernante, sino más bien sostenido en instituciones privadas en pugna por una participación del mercado, y la imposibilidad regulatoria de los gobiernos que se torna en permisividad y complicidad.
Así, se puede leer en la fotografía del niño obeso crucificado en el cuerpo adulto de Ronald McDonald, en tanto la libre competencia, y la libertad de expresión, cómo los discursos de época permiten y estimulan el desarrollo de una marca mundial, que prima sobre sus efectos en la salud de niñas y niños. También es posible leer así la fotografía que muestra a un niño con una herida crucificado en el cuerpo de un médico, donde los bienes a ser transados, según las leyes del mercado, se mueven desde los lugares donde se producen más eficientemente a los lugares donde la demanda ofrece un mejor precio, lógica que permite que el riñón de un niño nacido en una favela en Brasil, sea vendido en Europa/Estados Unidos.

Las fotografías relativas al accidente nuclear en la planta de Fukushima en Japón, a las masacres llevadas a cabo con armas en entidades de educación en Estados Unidos, y la guerra civil en Siria, parecen tener un campo de acción geográficamente más determinado, pero que se desborda hacia otros lugares por la venta de armas de empresas estadounidenses a Centroamérica, la migración de los sirios a Europa, y las emisiones al mar de líquidos de enfriamiento y trazos de partículas radiactivas que han sido encontradas fuera de Japón. Aunque pareciera que el ejemplo de Siria corresponde más a una guerra civil tradicional, la perspectiva se amplía cuando nos preguntamos la proveniencia de las armas utilizadas por los grupos rebeldes y las razones por las que se les entregaron; las armas de ISIS por ejemplo, fueron entregadas por Estados Unidos 
como parte de sus estrategias post-11 de setiembre y, más allá de esto, corresponde preguntarse por la necesidad de los conflictos armados para el sostenimiento y crecimiento del mercado de armas. En el caso de Japón y Estados Unidos, el mercado de energía en sociedades post-industriales y tecnológicas, y el mercado de armas proveído por la industria de armas estadounidense, nuevamente prevalecen sobre la ley de prohibición del incesto, produciendo campos y redes de excepción de la misma.

\section{Artista como parrhesiasta}

La forma de develamiento crítico a través del arte que realiza Ravelo, ese gesto artístico, argumentaré, puede pensarse como un acto de un parrhesiasta tal y como lo trabaja Foucault en su libro El coraje de la verdad, entendido como un forma de enunciación de verdad en un acto creador.

En el seminario dictado en 1983-1984 titulado El coraje de la verdad, Foucault se detiene en las formas aletúrgicas de la Antigüedad; aleturgia, significa manifestación de verdad $\mathrm{y}$, en este sentido, las formas aletúrgicas serían el " [...] conjunto de los procedimientos posibles, verbales o no, mediante los cuales se saca a la luz lo que se plantea como verdadero, en oposición a lo falso, a lo oculto, a lo indecible, a lo imprevisible, al olvido." (2010, p. 19). Estas estarían inscritas dentro de un principio más amplio del cuidado de sí -epiméleia heautóu- y dentro de este el conócete a ti mismo -gnothi seautón.
Una de las formas aletúrgicas es la parrhesía como modalidad de decir lo veraz, que le permite a Foucault pensar la forma en que un sujeto que dice la verdad es reconocido por los demás y por sí mismo; es decir, la relación entre sujeto y verdad. Para decir la verdad sobre sí, se requiere de otro que acompañe, sin embargo, no cualquiera podía acompañar el ejercicio, sino alguien que tuviera un hablar con franqueza. Esa manera de hablar se llamaba parrhesía. En algunos textos antiguos la parrhesía se opone a la adulación; en otros, se usa como una forma de decir todo sobre la verdad sin enmascararla, la cual requiere de un compromiso subjetivo: enunciar la verdad ata al parrhesiasta a la misma, pero lo más importante es que haya cierto riesgo en decir esa verdad. De esta manera " [...] es menester que el sujeto, al decir una verdad que marca su opinión, su pensamiento, su creencia, corra cierto riesgo, un riesgo que concierne a la relación misma que él mantiene con el destinatario de sus palabras" (2010, p.30).

En el acto parrhesiasta se corre el riesgo de ofender, importunar, disgustar al otro, al punto de que pueda responder violentamente y el que habla arriesgue su vida. "De alguna manera, el parrhesiasta siempre corre el riesgo de deshacer, de poner fin a la relación con el otro que, justamente, hizo posible su discurso" (2010, p.30). En el juego de la parrhesía estaría también implícito el coraje de quien recibe la verdad allí anunciada a pesar del malestar que le genere. 


\section{Artículos}

La parrhesía no es un oficio, o una técnica, o un ejercicio profesional; es más bien una actitud, una forma de virtud, una papel que se juega en la sociedad, un modo de enunciación veraz. El parrhesiasta no es un profeta porque no dice la verdad en forma de un porvenir enigmático en nombre de un Dios; más bien enuncia la verdad en forma clara y comprometida, dice su verdad aceptando las consecuencias que esto conlleva:

El parrhesiasta no ayuda a los hombres a franquear de cierta manera lo que los separa de su porvenir [...]. Los ayuda en su ceguera, pero en su ceguera acerca de lo que son, acerca de ellos mismo, y por lo tanto no de una estructura ontológica sin de alguna falta, distracción o disipación moral, consecuencia de una desatención, una complacencia o una cobardía. (Foucault, 2010, p. 35)

Esta develación no busca una interpretación por parte de su receptor, sino un actuar comprometido en relación con esa verdad dicha. No es un sabio, que habiendo reflexionado sobre la verdad guarda silencio y al decirla lo hace de manera enigmática. En este sentido,

[...] su papel específico no es decir el ser de la naturaleza y las cosas [...] el decir veraz del parrhesiasta que siempre se aplica, cuestiona, apunta a individuos y situaciones para decir lo que son en realidad, decir a los individuos la verdad de sí mismos que se oculta a sus propios ojos, revelarles su situación actual, su carácter, sus defectos, el valor de su conducta y las consecuencias eventuales de la decisión que tomen. (2010, p. 38)
La práctica de la parrhesía surte sus efectos en el alma -psykhé- y su objetivo es la formación de un ethos, o la de un sujeto ético, "La verdad del parrhesiasta es una que surge más bien como consecuencia de un ethos creador" (Retana, 2015, p. 244).

La instalación humana de Ravelo captura, revela, devela, saca a la luz una coreografía social de la que participamos pero no queremos ver, y mucho menos dar cuenta de ella. Nos muestra la grilla de inteligibilidad en su luz más oscura, enuncia los discursos que articulan un poder vestimentario cuyos efectos son campos o redes de excepción de la ley de prohibición del incesto a través de los cuales vulneramos la niñez, momento de construcción subjetiva ya de por sí vulnerable. Ese gesto artístico como acto enunciación creativo generó una reacción fuerte en el público que lo recibió a través de las redes sociales. Justamente, Ravelo lo dio a conocer a través de su página de Facebook Eric Ravelo Art, y ese mismo espacio por medio del cual se hizo viral, fue el que lo censuró. En otras palabras puso en riesgo la relación con el otro que le permitió su acto de enunciación de verdad, al punto de recibir amenazas de muerte.

El ensayo artístico convocó a muchos, los cuales lo compartieron con otros, invitados todos a reconocer allí una verdad, a preguntarnos sobre nuestra participación en eso que se mostraba, a cuestionarnos sobre la posición que tenemos y tendríamos que tener frente a ese estado de las cosas. A mí, 
por ejemplo, me llevó a escribir este ensayo.

Los intocables, resulta un título polisémico, como lo explica Kekena Corvalán en un artículo del leedor.com: "Es interesante el nombre de la serie, los intocables, que alude a un desplazamiento de sentido entre lo que debería ser y lo que es, ya que, perversamente, los intocables deberían ser los niños, pero terminan siendo los varones que abusan de ellos" (Corvalán, 2013). Eso que se plasma en esas fotografías incomoda, desacomoda, remueve, conmueve, perturba, penetra, inquieta, convoca, persiste, y hace preguntas difíciles de contestar, pero necesarias. Pienso que el gesto artístico de Ravelo es un acto parrhesiasta que devela una verdad con una estética clara, directa y simple y una composición que hace que lo que se dice sea ineludible para el receptor, conmoviéndolo a una reflexión ética.

\section{Contexto sobre fotografía 1: "Iglesia Católica"4. Muestra un sacer- dote de espaldas formando una cruz con su cuerpo y un niño en calzoncillos crucificado.}

Abriéndose la discusión pública sobre los casos de abuso sexual de niños por parte de sacerdotes de la Iglesia Católica a partir de la década de los 70, fue en los años 90 y 2000 donde el debate creció en intensidad a partir de una oleada de denuncias en diferentes partes del mundo. Entre el 2000 y el 2010 surgieron denuncias en Australia, Austria, Sudáfrica, Brasil, México, Estados Unidos, Irlanda, Italia, Argentina, Alemania, Holanda, Noruega, Polonia, Brasil, y Chile, con una cobertura mediática importante (BBC Mundo, 2010). Se ha evidenciado que el Vaticano inicialmente promovía guardar en secreto estos casos bajo amenaza de excomunión, cambiar a los sacerdotes de parroquia lo cual ponía en riesgo a más niños, y manejar los casos localmente. A partir del incremento de las denuncias del 2000 en adelante, se emitieron directrices de remitir los casos de sacerdotes pedófilos a Roma. Finalmente, a partir del 2010, se le pidió a los obispos reportar los casos de abuso a las autoridades civiles locales.

En el 2014 el Comité de Protección de los Derechos de los Niños de las Naciones Unidas hizo público un informe, resultado de seis años de investigación sobre el tema, donde acusa a la Iglesia Católica de violar sistemáticamente la Convención de los Derechos de los Niños; este, critica la falta de controles para detener y enjuiciar a los acusados de abuso sexual y denuncia la poca colaboración que recibió por parte del Vaticano para la elaboración del estudio. El reporte explicita, "El Comité está particularmente preocupado que, ante las numerosas alegaciones de abuso sexual, la Santa Sede eligió preservar la reputación de la Iglesia al proteger a los perpetradores de los delitos sobre el interés de los niños" (BBC, 2014, párr. 9).

${ }^{4}$ Dichas imágenes pueden ser vistas en el sitio web Erikravelo.info 


\section{Artículos}

Contexto sobre fotografía 2:

"Turismo sexual". Muestra un hombre turista de espaldas formando una cruz con su cuerpo y una niña descalza crucificada.

El turismo sexual con niños es una forma de explotación comercial sexual de niños(as) que utiliza la infraestructura de la industria turística (The Code, 2012). Se estima que alrededor del mundo, dos millones de niños y niñas son explotados sexualmente cada año. El tráfico de niños(as) para propósitos sexuales se ha convertido en un negocio trans-nacional altamente lucrativo, la industria de crimen organizado más grande después de armas y drogas. La trata de niñas con propósitos sexuales incluye la prostitución y la pornografía, aunque incluye a niños y a niñas, es más prevalente con niñas, a edades tan tempranas como los 5 años. Se da en todo el mundo y es más común en países golpeados por la pobreza, la inestabilidad política y la corrupción. Los factores de vulnerabilidad incluyen la pobreza en los hogares, el abuso sexual y físico en sus familias que precipita un continuum de la violencia, tener un estatus legal incierto, o vivir cerca de destinos turísticos o bases militares.

En muchos destinos turísticos, el público, los turistas y las agencias que aplican la ley, toleran o no se dan cuenta que se está llevando la prostitución infantil. Las niñas y niños sufren severos problemas físicos y psicológicos y, como resultado de la explotación sexual comercial, experimentan estigmatización, traición, e impotencia, lo cual les dificulta enormemente las posibilidades de escape y la reintegración a la sociedad (Selinke y Smolensky, 1996).
Contexto sobre fotografía 3:

"Trata de órganos". Muestra un médico de espaldas formando una cruz con su cuerpo, y con instrumentos para llevar a cabo cirugías en ambas manos, $y$ un niño en calzoncillos crucificado, a la par una hielera cerrada con cinta adhesiva.

La trata de órganos es una forma de trata de personas cuya mayor incidencia se da en mujeres, niños y niñas en situaciones de vulnerabilidad económica y social. Grupos de crimen organizado convencen a las personas con promesas falsas para que vendan sus órganos a un precio bajo, que luego transfieren a los compradores de órganos a un precio mucho más alto. La principal diferencia entre la trata de órganos y otros tipos de trata reside en que los intermediarios son de sectores respetados de la sociedad, como el caso de profesionales de la salud. El órgano más comúnmente transado es el riñón, pero se trafica también con el hígado, pulmón y páncreas, y otros tejidos y células. Como no es posible preservar los órganos por mucho tiempo fuera del cuerpo, es difícil diferenciar las estadísticas de trata de personas de las de trata de órganos. Muchas veces las personas en situaciones de pobreza que acceden a vender sus órganos no reciben el pago acordado (UN, 2014).

Es posible ordenar un órgano en Internet, y también es posible si se necesita dinero desesperadamente vender un riñón a un intermediario. La Organización Mundial de la Salud calcula que los traficantes alrededor del mundo obtienen ilegalmente 7000 
riñones al año, se llevan a cabo 10,000 operaciones de mercado negro al año, y que $10 \%$ de los trasplantes de riñón a nivel mundial son posibles por la trata de órganos (Bindel, 2013). La policía en México sospecha que el cartel de los Caballeros Templarios está involucrado con el secuestro de niños para cultivo de órganos. Capturan a los(as) niños(as) los llevan a casas rentadas con equipo médico donde se remueven los órganos (Rodríguez, 2014). Esto ocurre en otros países en desarrollo plagados por la pobreza en todo el mundo, si estas personas ya están vulnerabilizadas por el sistema, con mayor razón se dificulta su protección y la persecución de los criminales organizados.

\section{Contexto sobre fotografía 4:}

"Armas en Estados Unidos". Muestra un hombre con botas y pantalón estilo ejército y una sudadera con capucha, en cada mano tiene un arma y a su lado otra, está de espaldas formando una cruz con su cuerpo, y una niña con uniforme de escuela crucificada.

Esta foto hace alusión a los tiroteos en centros educativos en Estados Unidos y la alta disponibilidad de armas que tienen los ciudadanos. Aunque las tasas de criminalidad en las ciudades de Estados Unidos no son mucho más altas que en otras ciudades en países desarrollados, sí tienen una tasa más alta de homicidios porque los criminales tienen más acceso a armas de fuego y, por lo tanto, es más probable que la víctima muera (Cook y Goss, 2014). Estados Unidos tiene la tasa más alta de tiroteos en centros educativos del mundo; CNN reportó en junio de 2014 un tiroteo cada 5 semanas (Fantz y Knight, 2014). Jessica Winter de slate.com argumenta que después de cada uno de los episodios de tiroteos en centros educativos la discusión sobre controlar la tenencia de armas se intensifica, pero rápidamente la conversación se torna hacia otros detalles del hecho como la misoginia, el racismo, o la forma en que se aceptan los estudiantes en las universidades, a pesar de los intentos de los grupos de presión, algunos senadores y el mismo presidente Obama de abrir un debate nacional con consecuencias (2015).

La NRA (Asociación Nacional de Rifles) promueve y hace lobby político a favor de la expansión de los derechos de portar armas; ninguna legislación a la que la organización se ha opuesto se ha convertido en ley. "Cuando la muerte violenta de 20 niños de primer grado no puede resultar en nuevas y significativas medidas sobre el control de armas, entonces tal vez - si tienes una cierta forma de pensar - es el momento de echar atrás en el tema de control de armas" (Winter, 2015, párr. 12). Estados Unidos tiene la tasa de tenencia de armas más alta del mundo, 88.8 por 100 residentes (Vici Media, 2015). El país norteamericano fue fundado en 1776 y ha estado en guerra 222 años del total de 239 de existencia como estado (Washingonblog.com, 2015). 
Contexto sobre fotografía 5:

"Accidente nuclear en Japón". Muestra una persona con un traje protector usado en lugares contaminados por accidentes nucleares, de espaldas formando una cruz con su cuerpo, y un niño en calzoncillos crucificado.

El 11 de marzo de 2011 hubo un terremoto y tsunami llamados Töhoku. Además de las 16,000 muertes por los desastres naturales en sí mismos, se dio un accidente en la Planta de Energía Nuclear de Fukushima a raíz del tsunami principalmente. El accidente produjo fallos en el equipo que terminó en la liberación de isótopos radioactivos al ambiente y de agente refrigerante al mar. La preocupación por el accidente de Fukushima toma fuerza a la luz del antecedente del accidente nuclear en Chernóbil en 1986, después del cual el Comité de Naciones Unidas sobre los Efectos de la Radiación Atómica indica que a partir del 2005 se reportaron más de 6,000 casos de cáncer de tiroides en los niños y adolescentes expuestos en Ucrania, Rusia y Bielorrusia. Aunque las cantidades de radiación emitidas fueron significativamente menores, en el caso de Fukushima, y las medidas de protección de la población fueron rápidas y efectivas, existe debate entre los científicos sobre los efectos posibles sobre la salud de la exposición prolongada a niveles bajos de radiación, que no necesariamente serían registrables por la epidemiología, por ejemplo, los efectos sobre el sistema inmune. La población tiene gran desconfianza de la información recibida de funcionarios públicos y médicos porque perciben que en la toma de decisiones prevalece el interés de mantener la producción de energía nuclear por sobre la salud de los ciudadanos (McCurry, 2014). En lo que están de acuerdo muchos científicos es en las consecuencias psicológicas sobre la salud de saber que un contaminante no visible podría tener efectos negativos sobre las personas. Un estudio realizado por el Centro Nacional para la Salud y el Desarrollo de la Niñez encontró que en las áreas afectadas por el desastre del 2011, uno de cada cuatro niños y niñas sufren depresión, ansiedad y otros problemas mentales (Kageyama, 2014).

\section{Contexto sobre fotografía 6:}

"McDonald's". Muestra a Ronald McDonald (payaso que representa la marca) de espaldas formando una cruz con su cuerpo, y un niño obeso en calzoncillos crucificado.

Según la Organización Mundial de la Salud, la obesidad infantil es uno de los retos más importantes para la salud pública en el siglo XXI. Mientras que en el 2005 había 20 millones de niños(as) con obesidad, para el 2013, 42 millones de niños y niñas menores de 5 años tenían sobrepeso, 31 millones vivían en áreas urbanas de países en desarrollo. Las causas del incremento en los niveles de obesidad infantil son, por un lado, un cambio en la alimentación hacia comidas ricas en grasas y azúcares y baja en vitaminas y minerales, y una tendencia a disminuir la actividad 
física. Hay una alta probabilidad de que un niño o niña con obesidad se convierta en un adulto(a) con obesidad (WHO International, 2015). Al comer en McDonald's un combo agrandado de Big Mac, significa la ingesta de 1600 calorías, que sería más que el total de contenido calórico que necesita un niño(a) en un día (Burros, 2002). En las últimas dos décadas en Estados Unidos se ha duplicado la prevalencia de la enfermedad llamada hígado graso no-alcohólico en niños y adolescentes, cuyas causas son una dieta pobre y exceso de peso (O’Connor, 2014). Sólo en Estados Unidos, McDonald's es dueño del $17 \%$ de la industria de restaurantes de servicio-limitado, la cuota más grande que es tan grande como la combinación de las siguientes cuatro empresas. Además tiene afiliados y franquicias en todo el mundo. Del 2008 al 2011 las ventas en EEUU subieron un 13\%. A pesar de críticas directas como el documental Super Size Me y cuestionamientos sobre su participación en el incremento de la obesidad infantil, la empresa gasta $\$ 2$ billones de dólares en publicidad y propaganda, el presupuesto más alto de la industria (O’Brian, 2012).

\section{Contexto sobre fotografía 7: \\ "Guerra en Siria”. Muestra a un soldado con la bandera siria en el casco, de es- paldas formando una cruz con su cuer- po, y una niña descalza crucificada.}

UNICEF calcula que 14 millones de niños han sido afectados por el conflicto en $\mathrm{Si}$ ria, muchos de estas niñas y niños están atrapados en áreas que han sido aisladas por las batallas y, por lo tanto, no tienen acceso a ayuda. Médicos sin fronteras estima que en la ciudad de Aleppo trabajaban 2500 doctores antes del conflicto, y hoy sólo quedan aproximadamente 100 (D'Urso , 2015). El sistema de salud de Siria ha colapsado y así un alto número de niñas y niños están muriendo de enfermedades crónicas y prevenibles, y los sobrevivientes sufren de "condiciones de salud medievales". En el 2014 el grupo Save the Children calculó que al menos 1.2 millones de niños habían huido a países vecinos, 4.3 millones están en Siria y necesitan ayuda humanitaria, y más de 10, 000 han muerto en la violencia (Gladstone, 2014).

\section{Referencias:}

Agamben, G. (2003). Estado de excepción: Homo sacer, II, I. Buenos Aires: Editorial Adriana Hidalgo Editora.

BBC Mundo. (2010). Cronología de los escándalos de abuso sexual dentro de la Iglesia Católica. BBC. Recuperado de http://www.bbc.com/mundo/ internacional/2010/03/100326_timeline_abuso_sexual_iglesia_pl.sht$\mathrm{ml}$ ? source $=$ pepperja $\mathrm{m} \&$ publisher I $\mathrm{d}=41543 \&$ click $\mathrm{Id}=1535341752$

BBC Mundo. (2014). Abuso a menos: los detalles de la acusación de la ONU al Vaticano. BBC. Recuperado de http://www.bbc.com/mundo/noticias/2014/02/140205_denuncia_onu_ vaticano_amv?source=pepperjam $\&$ publisherId $=41543 \&$ click $I d=1535335959$ 


\section{Artículos}

BBCMundo.(2014). Cinco preguntas sobre el escándalo de abuso sexual en el Vaticano. BBC. Recuperado de http://www.bbc. com/mundo/noticias/2014/02/140205_ vaticano_abuso_onu_preguntas_wb$\mathrm{m}$ ? source $=$ pepperja $\mathrm{m} \&$ publisherI $\mathrm{d}=41543 \&$ clickId $=1535317024$

Bindel, J. (2013). Organ Trafficking: a deadly trade. The Telegraph. Recuperado de http://www.telegraph.co.uk/ news/uknews/10146338/Organ-trafficking-a-deadly-trade.html

Burros, M. (2002). EATING WELL; McDonald's Fat Debate Goes On. The New York Times. Recuperado de http:// www.nytimes.com/2002/09/11/dining/ eating-well-mcdonald-s-fat-debategoes-on.html

Cook,P.yGoss,K.(2014). Inschoolrampages, the weapon matters. CNN. Recuperado de http://edition.cnn.com/2014/04/11/ opinion/cook-goss-pennsylvania-stabbing/index.html

Corvalán, K. (2013). Untouchable, de Erik Ravelo. Leedor.com. Recuperado de http://leedor.com/2013/08/17/ untouchable-de-erik-ravelo/

D'Urso, J. (2015). Millions of Children Are Trapped By War in Syria. Huffington Post. Recuperado de http://www.huffingtonpost.com/2015/03/12/syria-warchildren_n_6854612.html.

Fantz, A., Knight L. y Wang. K. (2014). A closer look: How many Newtown-like school shootings since Sandy Hook?
CNN. Recuperado de http://edition.cnn. com/2014/06/11/us/school-shootingscnn-number/index.html

Foucault, M. (2010). El coraje de la verdad: el gobierno de sí y de los otros. II Curso en el Collège de France (1983-1984). Buenos Aires: Fondo de Cultura Económica.

Gladstone, R. (2014). Report Cites "Devastating toll" on health of Syria's Children. New York Times. Recuperado de http:// www.nytimes.com/2014/03/10/world/ middleeast/report-cites-devastating-toll-on-health-of-syrias-children.html?_r $=0$

Kageyama, Y. (2014). As fears of Fukushima's Radiation Linger, Children Flee Homes for Distant Schools. The Huffington Post. Recuperado de http://www.huffingtonpost.com/2014/04/07/fukushima-radiation_n_5103582.html

McCurry, J. (2014). Fukushima's children at centre of debate over rates of thyroid cancer. The Guardian. Recuperado de http://www.theguardian.com/ world $/ 2014 / \mathrm{mar} / 09 /$ fukushima-children-debate-thyroid-cancer-japan-disaster-nuclear-radiation

News.com.au (2013). Artist Eric Ravelo puts children on The Cross for controversial project. News.com.au. Recuperado de http://www.news.com.au/technology/ artist-erik-ravelo-puts-children-onthe-cross-for-controversial-project/ story-e6frfro0-1226716863451

O’Brian, K. (2012). How McDonald's Came Back Bigger Than Ever. The New York Times. Recuperado de http://www.nytimes. 
com/2012/05/06/magazine/how-mcdonalds-came-back-bigger-than-ever. html?pagewanted=all

O'Connor, A. (2014). Threat Grows from Liver Illness Tied to Obesity. The New York Times. Recuperado de http://well.blogs. nytimes.com/2014/06/13/threat-growsfrom-liver-illness-tied-to-obesity/

Real Academia Española. (2011). Diccionario de la lengua española. Madrid: Editorial Espasa Calpe, S.A.

Retana, C. (2015). Las artimañas de la moda: una genealogía del poder vestimentario. Sano José: Editorial Arlekin.

Rodríguez, O. (2014). Child Organ Harvesting And Trafficking-Linked Arrest Made In México. The Huffington Post. Recuperado de http://www.huffingtonpost. com/2014/03/17/child-organ-harvesting_n_4982854.html.

Selinske, J. y Smolensky, C. (1996). Understanding Child Sex Tourism. Youth Advocate Program International. Recupera de: http://yapi.org/ csec-and-child-trafficking/.

The Code. (2012). Understanding Childe Sex Tourism. The Code. Recuperado de http://www.thecode.org/csec/ background/

United Nations. (2014). Organs for sale. $U N-$ RIC. Recuperado de unric.org. http:// www.unric.org/en/human-trafficking/27447-organs-for-sale

Vici media. (2015). A factual look at Guns in America. Vici media. Recuperado de americangunfacts.com.

Washingtonblog.com. (2015). America has been at war $93 \%$ of the time- 222 out of 239 years since 1776. Washintonblog. com. Recuperado de http://www.washingtonsblog.com/2015/02/americawar-93-time-222-239-years-since-1776. html

WHO International. (2015). Global Strategy on Diet, Physical Activity and Health. World Health Organization. Recuperado de http://www.who.int/dietphysicalactivity/strategy/eb11344/strategy_english_web.pdf

Winter, J. (2015) Giving Up on Gun Control. Slate. Recuperado de http://www. slate.com/articles/news_and_politics/ politics/2015/06/gun_control_debate_ we_re_not_having_one_after_charleston_and_we_haven_t.html. 